\title{
Agile Web Engineering (AWE) Process: Multidisciplinary Stakeholders and Team Communication
}

\author{
Andrew McDonald and Ray Welland \\ Department of Computing Science, University of Glasgow, Glasgow, Scotland. G12 8QQ. \\ \{andrew, ray\}@dcs.gla.ac.uk, http://www.dcs.gla.ac.uk/
}

\begin{abstract}
The Agile Web Engineering (AWE) Process is an agile or lightweight process that has been created to tackle the challenges that have been identified in Web engineering: short development life-cycle times; multidisciplinary development teams; delivery of bespoke solutions comprising software and data. AWE helps teams identify and manage the interactions between the business, domain, software and creative design strands in Web engineering projects. This paper gives an overview of the wide diversity of stakeholder roles reflected within AWE and how AWE tries to ensure communication between multidisciplinary sub-teams on large Web engineering projects.
\end{abstract}

\section{Introduction}

During September 2000 we decided to investigate traditional software engineering processes and methodologies and their application in Web engineering projects. From October until December 2000 we conducted a survey of commercial organisations involved in Web-based application development [7]. We carried out this survey by interviewing various different types of development stakeholder who contribute to the deliverables in a typical Web engineering project.

Across the seven organisations involved in our survey we concluded that in a development team of eight people: two will be from a technical or tradition software background; two will be from a creative design background; two will lead the team and the other two will be a domain and a business expert. Domain Experts are developer stakeholders who are responsible for issues associated with the application domain to which the Web application is being applied. Domain Experts are primarily responsible for the low-level integration and creation of content for Web applications. We believe that Domain Experts must be part of the Web development team. Business Experts are developer stakeholders who are responsible for business issues in the Web-based development team. Business Experts, in addition to providing content, are seen to provide guidance on achieving the business objectives of the Web engineering project. Business Experts are involved in contributing to the overall structure of the Web presence and in the high-level integration of data and software. We also view Business Experts as an essential part of any Web development team.

The multidisciplinary nature of Web engineering teams led us to think about how we could focus on the culturally diverse groups of people involved in Web engineering projects. This led us to consider an agile route [1] to solving the problems and is 
sues a Web engineering process will have to tackle. We felt the agile approach best suited the challenges facing a Web engineering process. Particularly with the agile focus on: people and interactions over processes and tools; working software over comprehensive documentation; customer collaboration over contract negotiation; and responding to change over following a plan [3]. The wide diversity of disciplines and the large percentage of non-technical developers required to create the deliverables in Web application development make the agile route with its focus on people and interactions ideally suited to Web engineering [2]. In addition, the focus on working software, or working deliverables that satisfy business objectives, is something that is severely lacking in Web-based development processes [7]. The highly volatile nature of the markets and technologies in Web-based development, make an adaptive process that focuses on collaboration and responding to changing customer requirements, essential for success.

The AWE process provides a comprehensive framework for the development of Web products as described in full in our technical report [6]. This paper focuses on those aspects of AWE that deal with stakeholder roles and team communication.

\section{AWE: Stakeholder Roles}

The AWE Process identifies the Stakeholder Roles within the development team that need to be addressed during large Web engineering projects: End-Users represent all the users of the proposed system in a development project using the AWE Process; Clients represent the body or bodies who are paying for the project development; Domain Experts as discussed previously; Business Experts as discussed previously; Software Engineers lead responsibility for technical issues associated with the project such as Web application performance and version control; Creative Designers lead responsibility for aesthetic issues, such as screen layout, colour and font usage; and Team Leaders are responsible for team guidance and project management. Often these roles are misunderstood, and the responsibilities/roles of each stakeholder blurred. This often leads to some of the following fundamental mistakes during project development.

Validating the Web deliverables using the Client rather than a sample of EndUsers. It is essential that project deliverables are validated against the business objectives using a sample of End-Users using proven well-understood techniques [8]. Often Clients are used to validate deliverables, unfortunately this can often lead teams to lose usability and business focus of the deliverables being produced [7], [9].

Lack of Business Experts and Domain Experts. Many organisations view the construction of Web-based applications as another software activity. Thus these organisations resource Web-based projects the way they would any other software development project. This often leads to the Software Engineer and Creative Designers making decisions regarding the product and its content, which they are not knowledgeable enough to do successfully in isolation from Business and Domain Experts.

Lack of co-operation/collaboration between Software Engineer and Creative Designer. In order to create the browser experience that best helps the project achieve its objectives it is essential both the Software Engineer and Creative Designer appreciate 
the contribution made by other roles in order to achieve the correct balance between function (usability) and form (aesthetic issues).

Poor leadership/management skills. Often if the Team Leader's background is in one of the other developer stakeholder roles, then the Team Leader can often be found to side with this developer stakeholder role during discussions/conflicts with other developer stakeholders. It is essential that the Team Leader be seen to be fair and always resolve conflicts in the best interests of the project in question.

AWE tries to address these issues by explicitly incorporating non-technical and technical stakeholder roles into the development team. The concept of small multidisciplinary development teams is something that Microsoft Solutions Framework (MSF) [4], [5] also advocates. However the cluster roles described in MSF [5] cover only those roles associated with traditional software development responsibilities, reflected within AWE's Team Leader and Software Engineer roles, together with consideration of usability issues. AWE goes much further to include roles reflecting the Business, Domain and Creative Design models in addition to those reflected in the traditional software development models. For a more detailed discussion of stakeholder roles reflected in AWE see our recent technical report [6].

\section{Orthogonal Uni-discipline Developer Communication}

One criticism levelled at other agile processes, is their inability to work beyond small teams of developers. We believe that AWE can scale beyond the limitation experienced by other agile processes. We use the term Orthogonal Uni-discipline Developer Communication to describe communication between similar types of developer on different teams working on the same project or Web presence. We believe that orthogonal uni-discipline developer communication will assist AWE in scaling to large numbers of developers due to the nature of large Web engineering projects.

Consider a large software engineering project to develop a new operating system. The developers will be split into smaller teams, with each team being challenged with a different type of problem. For example, one team will be responsible for the kernel, one team for the windowing system, one for device drivers, etc. Each team may be using similar technologies and techniques to build their respective deliverables, however every other team will view the deliverables primarily as a black box, through predefined interfaces, as each team will be working on a different type of problem space.

In large Web engineering projects, developers are often organised into a number of smaller teams, where deliverables are viewed as black boxes through pre-defined interfaces, just like large software engineering projects. However, each team will be working on similar types of problem spaces. For example, a large number of separate teams on the same Web presence will be concerned with Web-based sign-on, and will want to leverage the same development effort across multiple teams to achieve Webbased single sign-on. The goal being to reduce development effort and enhance the End-User experience across multiple team's deliverables for the same Web presence.

We envisage that each sub-team on a Web engineering project will include a number of different specialists. However, there will be a need for the specialists to communicate across teams, orthogonally to individual team structures. So, for example, all the creative designers will meet to coordinate design activities, the domain experts 
to coordinate their components, etc. AWE recommends that this structure be formalised by having a coordination team with a leader for each of the specialisations liaising with the respective specialists within the teams. For a more detailed discussion on orthogonal uni-discipline developer communication see our recent technical report [6].

\section{Conclusions and Further Work}

We have completed our first industrial trial of the AWE process in a global Fortune 500 Financial Service Sector Company. This trial focused on the introduction of an Evaluation Phase to the organisation's Web engineering development process during the evolution and maintenance of a retail Internet banking Web-based application. Unfortunately, it was not possible to comprehensively explore all of the features described in the AWE process, including stakeholder roles and communication on large projects, during our first commercial trial. However the first trial showed the business sponsors the merits of AWE's Evaluation Phase. As a result further consideration of other AWE features is underway on the largest Web-based and Object-based project in the group globally. We hope to be able to report regarding these trials in more detail late in 2003.

\section{References}

1. Beck K. et al.: Manifesto for Agile Software Development, The Agile Alliance, (February 2001), http://www.agilealliance.org/

2. Cockburn A.: Characterizing People as Non-Linear, First-Order Components in Software Development, Humans and Technology Technical Report, TR 99.05, (October 1999)

3. Fowler M.: The New Methodology, MartinFowler.com, (March 2001), http://www.martinfowler.com/articles/newMethodology.html

4. Getchell S. et al.: Microsoft Solutions Framework Process Model v. 3.1, Microsoft Corporation White Paper (June 2002)

5. Haynes P. et al.: Microsoft Solutions Framework Team Model v. 3.1, Microsoft Corporation White Paper (June 2002)

6. McDonald A., Welland R.: Agile Web Engineering (AWE) Process, Department of Computing Science Technical Report TR-2001-98, University of Glasgow, Scotland, (2 December 2001)

7. McDonald A., Welland R.: Web Engineering in Practice, Proceedings of the Fourth WWW10 Workshop on Web Engineering, 21-30, (1 May 2001)

8. Nielsen J.: First Rule of Usability? Don't Listen to Users, Jacob Nielsen's Alertbox, (5 August 2001), http://www.useit.com/alertbox/20010805.html

9. Ramsay M., Nielsen J.: WAP Usability Déjà Vu: 1994 All Over Again, Report from a Field Study in London, Fall 2000, Nielsen Norman Group, (December 2000), Page(s): 4. http://www.nngroup.com/reports/wap 